DOI: https://dx.doi.org/10.24093/awej/vol12no4.11

\title{
The Voice of Learners on English Literary Texts: Passing on the Mantle
}

\author{
Norhanim Abdul Samat \\ Language Academy \\ Faculty of Social Sciences and Humanities \\ Universiti Teknologi Malaysia, Malaysia \\ Corresponding Author: norhanim@utm.my \\ Nur Alwani Syahirah Azmi \\ School of Education \\ Faculty of Social Sciences and Humanities \\ Universiti Teknologi Malaysia, Malaysia \\ Tina Abdullah \\ Language Academy \\ Faculty of Social Sciences and Humanities \\ Universiti Teknologi Malaysia, Malaysia
}

Received: $11 / 8 / 2021$

Accepted:10/26/2021

Published:12/15/2021

\section{Abstract}

This study examines how pre-service teachers assess the appropriateness of literary texts used by high school students in terms of learners' age, linguistic needs, and language proficiency. It also aims to determine the relevance of the texts used to learners' cultural understanding. The participants in this study were five pre-service teachers who participated in a content analysis study of five literary texts. They analyzed the content of the texts using the four categories of textbook evaluation criteria proposed by Tomlinson (2001), namely, media-specific criteria, content-specific criteria, learner-specific criteria, and language criteria. The evaluation results were positive. All participants agreed that all five texts were appropriate for high school learners, with average levels of compliance ranging from moderate to appropriate. In addition to selecting texts that are appropriate for the learners' language level, the topics and issues addressed in the texts should also be appropriate for the learners' interest, so the selection of literary texts is crucial. Finally, more local texts should be selected for the English literature curriculum to highlight local cultures and practices. It is expected that this study will contribute to English language teaching as the findings of this study will provide necessary information to those who are concerned with the selection of appropriate literary texts for schools. In addition, this study will raise awareness among teachers and curriculum designers of the need to consider learners' level of competence when evaluating and selecting from the many literary texts available.

Keywords: content analysis, evaluation, literary text, literature, textbook, cultural background, language proficiency, curriculum designers

Cite as: Abdul Samat, N., Azmi, N. A. S., \& Abdullah. T. (2021). The Voice of Learners on English Literary Texts: Passing on the Mantle. Arab World English Journal, 12 (4) 153-166.

DOI: https://dx.doi.org/10.24093/awej/vol12no4.11 
Arab World English Journal (AWEJ) Volume 12. Number 4. December 2021

The Voice of Learners on English Literary Texts

Abdul Samat, Azmi, \& Abdullah

\section{Introduction}

In March 2000, the Malaysian Ministry of Education recognized the role of literature as an important factor in improving learners' English proficiency and language skills. This was done by reintroducing literature into the Malaysian English language curriculum as a taught and tested component for all high school learners in Malaysia (Sivapalan \& Subramaniam, 2008). Classroom teachings use the given literary texts, including selected poems, short stories, novels, and drama. This interest in bringing different texts and materials into the classrooms is an effective way of promoting positive perception among the learners in learning English. However, this move will improve the learners' interest and perception if only the literary texts used are attractive and understandable by all the learners.

For this study, we shall evaluate the literary texts used by Form Four learners (upper secondary education usually aged 16 and above) at selected high schools in the south of Malaysia. These learners used a set of selected texts, which mainly consist of two poems, two short stories, and a drama. If the Ministry of Education decides the literary texts relevant to the context of Malaysia, these texts could shape learners' ways of thinking and character development.

For this reason, the texts thus must be assessed and evaluated following specific standardized criteria of English language material evaluation (Bobkina \& Dominguez, 2014). As such, this study will shed some light on the suitability of the selected texts. The benefits of introducing literature into the English language classroom in Malaysia can only be realized through a careful and deliberate selection of texts that are suitable for language learning. To enrich learners, it is essential to select texts that learners can reflect on and think about. According to Kebede and Milkitie (2018), when looking for literary works for language teaching, it is important to examine not only learners' motivation for the texts but also the cultural context and language of the texts. Collie and Slater (1990) suggested that text selection depends on "each particular group of learners, their needs, interests, cultural background and language level" (as cited in Kebede \& Milkitie, 2018, p. 1001). If the content is interesting enough, it will provide a new perspective on topics relevant to the learners' concerns.

A text that is deemed to be a close fit with the learners' cultural values might not only elicit more in-depth responses from them but can also emphasize the necessity of recognizing and extending learners' perspectives on various cultures and world views. According to Kebede and Milkitie (2018), learners might quickly lose interest and motivation while reading and using literary works in the English language, mainly when dealing with complex and difficult-tounderstand topics and ideas. These will result in a significant inability to integrate the target language into literary works for teaching (Kebede \& Milkitie, 2018).

Thus, the selection of texts should constantly consider the demands and levels of competence of the learners. Tevdosvka (2016) asserted that teachers, educators, and curriculum designers, especially those involved in curriculum development and design, should focus their attention on considering factors such as learners' age, language level, and background knowledge. Another factor to consider in the selection of texts is thematic consideration, which 
Arab World English Journal (AWEJ) Volume 12. Number 4. December 2021

The Voice of Learners on English Literary Texts

Abdul Samat, Azmi, \& Abdullah

encourages the use of specific topics that appeal to learners' interests and maturity levels. Human relationships such as kinship, friendship, or familial love, growing up, life problems, nature, patriotism, conflict, adventure, and science fiction are some of the topics that should be covered (Abdullah \& Hashim, 2007).

As mentioned earlier, the purpose of this study is to assess the appropriateness of literary texts for Form Four (high school) learners in southern Malaysia. The research questions are:

1. To what extent is the level of suitability of literature texts assigned to high school learners associated with the learners' age, linguistic requirements, and language competence?

2. How relevant are the text themes to the learners' culture?

The researchers chose to focus on the study of literary texts for Malaysian high schools for various reasons. First, we work as English teachers in higher education and schools where we noticed the challenges that teachers face when using literary texts. In addition, during the actual teaching and learning process, we noticed that learners had difficulties in understanding the context of literary texts. We believe that these issues could imply that specific literary texts were not appropriate for the learners' background and language abilities.

This study should contribute to English language education primarily in selecting literary texts for high school learners. It is hoped that this study can shed some light on the possible factors in the selection and evaluation of literary texts and provide insights for those concerned with the selection of appropriate literary works for use in schools. Furthermore, this research will raise awareness among teachers and curriculum designers about the need of considering learners' competence levels when evaluating and selecting literary works from available lists.

\section{Literature Review}

Literature in the English language began to be acknowledged as one of the sources for learning languages during the last twentieth century. Previously, it was noted that from the late 1950 s to the early 1980 s, the process of English teaching was primarily overlooked by the advanced discourse method, which demonstrates progressive, pragmatic language learning techniques with the primary goal of developing learners' communication abilities and operational skills (Hall, 2005). There was limited opportunity for creative development, especially in the context of language education.

It was not until the middle of the 80 s that some scholars and language practitioners began to include the aspects of literature as valuable language learning materials after those long days of desertion (Maley, 1989). This phenomenon is seen by referring to the long list of literary publications that began making their way in paving the comeback of literature in the language classroom (Gower \& Pearson, 1986 as cited in Khatib, Derakhshan, \& Rezaei, 2011).

The worth of authenticity that literature holds in its input for language acquisition since it is deemed authentic content is one example of what is viewed as an advantage of utilizing literature in the classroom. According to Calafato \& Gudim (2020), literary texts can meet the requirements for textual authenticity since literary works are authentic and were not explicitly created for use in textbooks. Maley (1989) further contributed to this fact by claiming that literary texts such as novels, dramas, and even poems are written with themes and content that 
Arab World English Journal (AWEJ) Volume 12. Number 4. December 2021

The Voice of Learners on English Literary Texts

Abdul Samat, Azmi, \& Abdullah

revolve around a variety of non-trivial issues while providing the reader with real, authentic input that has a personal connection and affects the individual.

Authenticity and sincerity, which are inherently present in literature, are essential factors in language acquisition, particularly in classrooms. This is seen in drama conversations, sentiment expressions, functional phrases, and views in contextualized utterances (Khatib, et al., 2011). As Calafato \& Gudim (2020) reported, literary texts are often the most important link to other cultures for learners who do not have the opportunity to interact with native speakers of the target language. The same is true for novels and real-life works based on the creative and artistic nature of the individual.

\section{Literary Texts in the Malaysian Curriculum}

Literature textbooks aim to introduce and provide learners with the necessary knowledge and information about the variety of literary texts in the English language. High school learners in Malaysia are not only provided with a standard English language textbook, but also literature textbooks. This category of literature component textbooks includes various literary works such as poetry, drama, and short stories. A novel is added to the literary content for a higher-level group of learners, aged 13 to 17, in addition to the literature textbooks. The selected texts could be both written by local authors or translated foreign literary works. It is said that the comprised texts which make up a textbook, are instead an essential tool in learning a language because, according to O'Keeffe and O'Donoghue (2015), textbooks have a significant influence in promoting a specific type of curricula. However, it must be organized purposefully, gradually from the content to its structure, as they are highly significant for the promotion of a specific vision of curriculum.

It was only in March 2000 that the Malaysian Education Ministry mandated the inclusion of literature in the curriculum. All learners must read literary works. Consequently, a fixed selection of prescribed poetry, novels, short stories, and drama are the primary text types used in Malaysian schools. However, the absence of other types of literary texts such as excerpts from dramas or even a whole range of English language works that deal with issues beyond the conventional norm, such as wars and the sense of nationalism for one's country or homeland, is evident from the text selection (Chitravelu et al., 2008, cited in Sanub \& Yunus, 2016). Ghazali et al. (2009) in their study pointed out that language teachers and curriculum writers invest a lot of time in selecting and designing their materials to reduce the gap between learners' difficulties in understanding the texts they use and ensuring that literary texts are within local and cultural boundaries. Furthermore, teachers and syllabus writers must decide which adapted foreign texts to include, the goals of the chosen materials, and the alignment of activities that may be done to delve into the texts to encourage the development of language abilities.

\section{Criteria for Literary Texts Selection}

According to Gopal and Mahmud (2016), text selection is a crucial component in making literature a distinct tool for language acquisition, self-enrichment, and cultural appreciation. According to Maley (1989), language learners may soon face several problems if they do not understand the factors to be considered in selecting appropriate literature (as Khatib et al., 2011). For instance, as Mussa \& Fente (2020) reported, the language level of the texts makes it difficult for learners to cope with them and the culture portrayed in them is far from their socio-cultural background, which makes it difficult for them to understand the texts (p. 1209). Therefore, it 
should be emphasized, that selecting texts is generally a difficult task for teachers and syllabus writers.

According to Khatib et al. (2011), those involved in selecting literary texts should be particularly cautious about such essential and crucial elements as language learners' competence, age, gender, and learner's prior knowledge, which should be the rules for literary text selection. In their study of the level of suitability of literary texts used by high school learners, Arshad, Othman, and Chew (2009) discovered that cultural backgrounds, experience, and expectations should be considered in addition to the listed criteria. Degwale \& Gashaye (2020) also argued that literary texts provide a broad range of possibilities to learn multi-dimensional uses of the language, demonstrating the need to choose relevant literary works for language instruction.

Most researchers believe that besides choosing and selecting texts that cater to language learners' level of proficiency, the theme and issues discussed should be in line with learners' interests. As a result, it is critical for instructors, educators, and curriculum designers to select texts for the English language syllabus that are diverse in terms of genres, topics, and learners' language levels.

\section{Methods}

In this current study, the researchers employed a qualitative approach to collect and analyze the data. The descriptive qualitative approach is based primarily on its sense of inductiveness, which focuses on the specific situation, and emphasizes word form rather than numbers (Maxwell, 2012). It was determined that the data identified in this study would be analyzed using content analysis in the form of a description. Content analysis is a type of document analysis that examines written, spoken, or visual communication messages. The texts under analysis include two poems, Charge of the Light Brigade by Alfred and Lord Tennyson, The Living Photograph by Jackie Kay, two short stories, Tanjong Rhu by Minfong Ho (Singapore) and Leaving by M.G. Vassanji, and a drama text, The Right Thing to Do by Martyn Ford.

\section{Research Instruments}

The research instrument used in this study was a self-constructed evaluation checklist, adapted and modified from Lathif (2015). The structure of the list was suggested by Tomlinson (2001, pp. 30-32), Cunninsworth (1995, pp. 15-17), and Mukundan, Nimehchisalem, and Hajimohammadi (2011, pp. 104-105) based on the established criteria for quality textbooks. Some items were deleted, and, or modified. Others were classified into more specific categories, and a few new ones were developed to meet the study's requirements.

The checklists were distributed to five research participants who had previously received pre-service training. They analyzed the texts based on content, presentation (media), student criteria, and language use. Additional comments from participants in the comments section of the checklist were examined to provide further insight and information about their views of the texts. To preserve the originality of the texts studied, all wording and terminology discovered during the analysis were accurately referenced when discussing the results.

\section{Data Analysis}


Arab World English Journal (AWEJ) Volume 12. Number 4. December 2021

The Voice of Learners on English Literary Texts

Abdul Samat, Azmi, \& Abdullah

As a data analysis method, descriptive statistics were used to sum the total scores from all five participants for each assessment item on the given checklist, which were then converted to percentages. In the assessment checklist, P1 (Poem 1) refers to the poem, Charge of the Light Brigade, P2 (Poem 2) refers to the poem, The Living Photograph, SS1 (Short Story 1) refers to the short story, Tanjong Rhu, SS2 (Short Story 2) refers to the short story Leaving, and D1 (Drama 1) refers to the drama, The Right Thing to Do. We calculated the scores so that we could obtain the mean score for each sub-aspect. The average scores for the scales in the instruments are presented as follows.

\section{Results}

The following description presents the findings of this study.

\section{Suitability of the Literary Texts}

The table below illustrates the suitability of the literary texts in terms of the learners' age, linguistic needs, and language competence.

Table 1. Evaluation results on student-specific criteria

\begin{tabular}{|c|c|c|c|c|c|c|}
\hline \multirow[t]{2}{*}{ Area } & \multirow[t]{2}{*}{ Criteria } & \multicolumn{5}{|c|}{ Mean Score } \\
\hline & & $\mathrm{P} 1$ & $\mathrm{P} 2$ & SS1 & SS2 & D1 \\
\hline (1) & The appropriateness of learners' age & 87.50 & 100 & 87.50 & 100 & 100 \\
\hline \multirow{5}{*}{$\begin{array}{l}\text { Student } \\
\text { - } \\
\text { specific } \\
\text { criteria }\end{array}$} & The likelihood of interest to the learners & 54.17 & 100 & 54.17 & 79.17 & 83.33 \\
\hline & The engagement level between learners & 54.17 & 75.0 & 66.67 & 79.17 & 91.67 \\
\hline & $\begin{array}{l}\text { The presentations of each text in reflecting the } \\
\text { logical and coherence decision path }\end{array}$ & 75.00 & 75.0 & 83.33 & 79.17 & 83.33 \\
\hline & $\begin{array}{l}\text { The presentation of how each text can support } \\
\text { learners' reflection and evaluation of themselves }\end{array}$ & 83.33 & 100 & 87.50 & 95.83 & 91.67 \\
\hline & $\begin{array}{l}\text { The presentation of how each text can encourage } \\
\text { pupils to internalize diverse principles to } \\
\text { promote a sense of connection to the homeland, } \\
\text { nation, and country }\end{array}$ & 87.50 & 54.17 & 87.50 & 83.30 & 87.50 \\
\hline \multicolumn{2}{|c|}{ Total Mean Score $(\%)$} & 73.61 & 84.03 & 77.78 & 86.12 & 89.58 \\
\hline \multicolumn{2}{|l|}{ Criteria } & Fair & Good & Fair & Good & Good \\
\hline
\end{tabular}

Table one shows the text evaluation results for student-specific criteria. Two texts were categorized as "fair." The poem Charge of the Light Brigade with an overall average fulfillment score of $73.61 \%$, and the short story Tanjung $R h u$ received an overall average fulfillment score of $77.78 \%$. The other three texts: the poem The Living Photograph with $84.03 \%$, the short story Leaving with $86.12 \%$, and lastly, the drama text The Right Thing to Do with a mean score of $89.58 \%$, are classified as "good," by the participants.

From the analysis of the poem, Charge of the Light Brigade, three sub-criteria from the student-specific criteria are classified as "good," namely the appropriateness of learners' age $(87.50 \%)$, the presentation of how each text was able to support learners' reflection and 
evaluation of themselves (83.33\%), and the presentation of how each text can encourage pupils to internalize diverse principles to promote a sense of connection to the homeland, nation, and country $(87.50 \%)$. Other sub-criteria that are classed as "sufficient," include the chance of learners being interested $(54.17 \%)$ and the degree of student involvement $(54.17 \%)$, while the sub-criteria of the presentations of each text in reflecting the logical and coherence decision path scored $(75.0 \%)$ which is considered as "fair."

A study on the poem The Living Photograph found that four sub-criteria are classified as "good," namely the appropriateness of learners' age (100\%), the likelihood of interest to the learners $(100 \%)$, and the presentation of how each text can support learners' reflection and evaluation of themselves (100\%). The other three sub-criteria, which are the engagement level between learners $(75.0 \%)$, the presentations of each text in reflecting the logical and coherence decision path (75.0\%), and the presentations of how each text can encourage pupils to internalize diverse principles to promote a sense of connection to the homeland, nation, and country (54.17\%) are categorized as "sufficient."

Likewise, a review of the short story, Tanjung Rhu shows that only one out of six subcriteria is categorized as "sufficient," namely the likelihood of interest to the learners (54.17\%). In contrast, the engagement level between learners (66.67\%) is categorized as "fair." The other four sub-criteria are "good," which are the appropriateness of learners' age in par with the text (87.50\%), the presentations of each text reflecting the logical and coherence decision path $(83.33 \%)$, the presentation of how each text can support learners' reflection and evaluation of themselves (87.50\%), and the presentation of how each text can encourage pupils to internalize diverse principles to promote a sense of connection to the homeland, nation, and country $(87.50 \%)$.

Similarly, the analysis of the short story Leaving shows that three out of five sub-criteria were rated as "good," namely, appropriateness for learners' age (100\%), presentation of how each text can support learners' reflection and self-evaluation (95.83\%), and presentation of how each text can encourage students to internalize various principles to foster a sense of attachment to the homeland, nation, and country $(83.30 \%)$. Three out of five participants rated SS2 as "fair," e.g., learner engagement $(75.0 \%)$, the likelihood of learner interest $(79.17 \%)$, and presentation of individual texts reflecting logical and coherent decision-making (85.0\%).

As for the drama text The Right Thing to Do, the participants categorized it as "good," in terms of the student-specific criteria scoring. It can be seen in the overall results for this category, which averaged $89.58 \%$. The sub-criteria on the appropriateness of learners' age reached $100 \%$ on scoring. In contrast, the other two sub-criteria, which are the likelihood of interest to the learners, and the presentations of each text in reflecting the logical and coherence decision path, recorded $83.33 \%$ on its evaluation score. The other two sub-criteria of the level of engagement between learners and the presentation of how each text can support learners' reflection and evaluation of themselves both scored 91.67\%. For the item, the representation of how each text can lead the learners towards the internalization of insight on diversity values for promoting the sense of belonging to the motherland, nation, and country achieved the mean score of $87.50 \%$. 
Arab World English Journal (AWEJ) Volume 12. Number 4. December 2021

The Voice of Learners on English Literary Texts

Abdul Samat, Azmi, \& Abdullah

Table 2. Evaluation results on language criteria

\begin{tabular}{|c|c|c|c|c|c|c|}
\hline \multirow[t]{2}{*}{ Area } & \multirow[t]{2}{*}{ Criteria } & \multicolumn{5}{|c|}{ Mean Score } \\
\hline & & P1 & $\mathrm{P} 2$ & SS1 & SS2 & D1 \\
\hline (2) & Density, pace, level of language clarity & 75.00 & 91.67 & 87.5 & 91.67 & 91.67 \\
\hline \multirow[t]{4}{*}{$\begin{array}{l}\text { Language } \\
\text { criteria }\end{array}$} & $\begin{array}{l}\text { The suitability of the language used } \\
\text { (word choice) with the student's } \\
\text { cognitive development. }\end{array}$ & 70.83 & 91.67 & 91.67 & 87.50 & 100 \\
\hline & $\begin{array}{l}\text { The texts arrangement based on the } \\
\text { difficulty level }\end{array}$ & 87.50 & 91.67 & 83.33 & 75.00 & 91.67 \\
\hline & $\begin{array}{l}\text { The standard of English language use of } \\
\text { the texts is under the language rules }\end{array}$ & 87.50 & 100 & 100 & 91.67 & 91.67 \\
\hline & $\begin{array}{l}\text { The use of the English language which is } \\
\text { appropriate to accommodate the process } \\
\text { of communication learning }\end{array}$ & 75.00 & 100 & 100 & 91.67 & 100 \\
\hline & Total Mean Score $(\%)$ & 79.17 & 95.00 & 92.50 & 87.50 & 95.00 \\
\hline \multicolumn{2}{|r|}{ Criteria } & Fair & \multicolumn{4}{|c|}{ Good } \\
\hline
\end{tabular}

Table two displays the text evaluation results for language criteria for each literary text. The results show that the participants recorded their somewhat positive responses. Looking at the overall mean, only the poem Charge of Light Brigade is rated as "fair" on the language criteria, with an overall compliance rate of $79.17 \%$. The other four texts, The Living Photograph, the short story Tanjong Rhu, the short story Leaving, and the drama The Right Thing to Do, are "good," with $95.0 \%, 92.5 \%, 87.50 \%$, and $95.0 \%$ respectively. This result indicates that all the texts are suitable for learners in terms of language criteria.

Table 3. Evaluation results on content-specific criteria

\begin{tabular}{|c|c|c|c|c|c|c|}
\hline \multirow[t]{2}{*}{ Area } & \multirow[t]{2}{*}{ Criteria } & \multicolumn{5}{|c|}{ Mean Score } \\
\hline & & $\mathrm{P} 1$ & $\mathrm{P} 2$ & SS1 & SS2 & D1 \\
\hline \multirow{4}{*}{$\begin{array}{l}\text { (3) } \\
\text { Content- } \\
\text { specific } \\
\text { criteria }\end{array}$} & $\begin{array}{l}\text { The conformity connecting the themes of } \\
\text { the selected texts and the planned themes } \\
\text { in the curriculum }\end{array}$ & 87.50 & 91.67 & 83.33 & 91.67 & 100 \\
\hline & $\begin{array}{l}\text { Suitability of issues, genre, and theme } \\
\text { found in the texts }\end{array}$ & 75.00 & 100 & 83.33 & 91.67 & 91.67 \\
\hline & $\begin{array}{l}\text { Amount of background and cultural } \\
\text { knowledge required to comprehend the } \\
\text { texts }\end{array}$ & 75.00 & 79.17 & 66.67 & 83.33 & 58.33 \\
\hline & The authenticity level of the texts & 95.83 & 100 & 83.33 & 87.5 & 87.50 \\
\hline
\end{tabular}


Arab World English Journal (AWEJ) Volume 12. Number 4. December 2021

The Voice of Learners on English Literary Texts

Abdul Samat, Azmi, \& Abdullah

\begin{tabular}{|r|c|c|c|c|c|c|}
\hline & $\begin{array}{l}\text { The aspects of gender, religion, and race } \\
\text { mentioned throughout the texts }\end{array}$ & 50.00 & 75.00 & 100 & 75.00 & 62.50 \\
\hline Total Mean Score (\%) & 76.67 & 89.17 & 83.33 & 85.83 & 80.0 \\
\hline Criteria & Fair & \multicolumn{5}{|c|}{ Good } \\
\hline
\end{tabular}

The items in Table three examine participants' views of the content of the texts. From the data shown, Charge of The Light Brigade is rated as "fair," by participants with a fulfillment level of 76.67\%. Participants rated The Living Photograph, Tanjung Rhu, Leaving, and The Right Thing to Do as "good," with scores of 89.17 percent, 83.33 percent, 85.83 percent, and 80.0 percent, respectively. The results indicate that the participants had a positive opinion of the content of the texts.

Table 4. Evaluation results on media-specific criteria

\begin{tabular}{|c|c|c|c|c|c|c|}
\hline \multirow[t]{2}{*}{ Area } & \multirow[t]{2}{*}{ Criteria } & \multicolumn{5}{|c|}{ Mean Score } \\
\hline & & P1 & P2 & SS1 & $\mathrm{SS} 2$ & D1 \\
\hline \multirow{2}{*}{$\begin{array}{l}\text { (4) } \\
\text { Media-specific } \\
\text { criteria }\end{array}$} & The appropriateness of the fonts & 100 & 100 & 100 & 100 & 100 \\
\hline & $\begin{array}{l}\text { The presentation of illustrations or } \\
\text { graphics which are functional and relevant } \\
\text { with the materials as learners' visual } \\
\text { support }\end{array}$ & 100 & 100 & 75.00 & 83.33 & 91.67 \\
\hline & Total Mean Score $(\%)$ & 100 & 100 & 87.50 & 91.67 & 95.84 \\
\hline & Criteria & \multicolumn{5}{|c|}{ Good } \\
\hline
\end{tabular}

The items in Table four explore the participants' opinions of the fonts and illustrations in the texts. Based on the data presented, all five literary texts assigned to the Form Four learners are rated as "good," as they achieve an average compliance rate of $100 \%, 87.50 \%, 91.67 \%$, and $95.84 \%$ respectively. This shows that all the texts met all the two sub-criteria in this area of assessment, namely, appropriateness of fonts (all the texts scored 100\%) and presentation of illustrations or graphics that are functional and relevant to the materials as visual supports for the learners.

\section{Discussion}

To analyze the relevance of selecting appropriate literary texts for learners, it is essential to examine the results of the overall assessment for all texts, including all four areas: learnerspecific criteria, language-specific criteria, content-specific criteria, and media-specific criteria. From the data obtained, it can be deduced that the selection of appropriate literary texts is important for learners mainly in four areas.

Concerning the first area of evaluation, student-specific criteria for selecting appropriate texts for learners are intended to increase learners' engagement level with the text. This is because learners' interest in the subject matter or the issues discussed plays a significant role in determining the learners' readability level of materials. From the findings, all participants agreed that the learners could engage well with the texts.

The second importance concerning the proper text selection in terms of the language area from the checklist is to assist learners with manageable learning materials following the interims 
of language difficulty. The language used should be only one level beyond a student's language competence (Tevdoska, 2016). This also ought to ease learners process of comprehending the texts and teachers' process of delivering the literature contents. Participants pointed out that some low-ability learners find it difficult to understand the poem The Charge of the Light Brigade due to complex words such as 'dismayed' and 'blundered'.

Content-specific is another important criterion for selecting literary texts because learners need to be familiar with the culture in the texts. Culturally standard texts or with local cultures will facilitate learning better because new and unfamiliar or wrongly assumptions on cultural points and practices may not suit learners' level of comprehension and conception. Furthermore, Lathif (2015) found that learners are more engaged in the teaching and learning process when resources are tailored to the learners' local culture. In the case of these textbooks, all five participants agreed that the content of the texts was appropriate and relevant to the learners.

Finally, the media-specific criterion is an essential criterion for text selection because it facilitates learners' comprehension of any text or written material they read. In this study, all five participants agreed that the size and length of the font used in all texts were appropriate for secondary learners.

By analyzing the study's findings, the research objectives were addressed in the study. The first research question was to determine the extent to which the literary texts were appropriate for high school learners in terms of age, linguistic requirements, and language competency. Poem 1, Charge of the Light Brigade, poem 2, The Living Photograph, short story 1, Tanjung Rhu, short story 2, Leaving, and the drama text, The Right Thing to Do were the five texts examined. The study's findings indicated that all the participants who evaluated the texts agreed that the key characteristics that should be considered during the selection of literary texts are authenticity, interest, entertaining, and being impactful to some extent. This should be done within the bounds of the learners' language skills.

According to Maley (1989), individuals involved in the selection of literary texts should pay special attention to essential and vital factors, including language learners' skills, age, gender, and prior knowledge. Unawareness of these factors while selecting appropriate literature texts may cause issues for language learners (Khatib, Derakhshan, \& Rezaei, 2011). All of these are strong arguments to do a literature text review to identify areas for development and change in the educational system. It should be emphasized, however, that if the assessment reveals that the text does not meet the stated requirements to meet the needs of the learner, the teacher has a clear signal that another text material should be chosen.

The second research question was to determine the relevance of the text themes to the learners' culture. The study reveals that the participants viewed the texts to be culturally appropriate for the learners' understanding. They agreed that the chosen texts were not too unfamiliar with the local culture. Tevdoska (2016) stated that it is critical to ensure that the literary works selected are culturally recognizable and approachable to both learners and teachers. Masyi'ah and Ciptaningrum (2018) shared a similar viewpoint, stating that when materials are chosen, they should include the learners' culture to engage learners in the teaching 
Arab World English Journal (AWEJ) Volume 12. Number 4. December 2021

The Voice of Learners on English Literary Texts

Abdul Samat, Azmi, \& Abdullah

and learning process and to serve as a medium for learners to maintain their local and national identities.

\section{Conclusion}

Before concluding, we would like to point out the limitations of this study. The purpose of this study was to investigate whether the literature texts used by high school learners are appropriate. We found that the results of the study may not be generalizable to all high school learners in the country due to the small sample size which includes two poems (Charge of the Light Brigade, and The Living Photograph), two short stories (Tanjong Rhu and Leaving), and a drama text entitled The Right Thing to Do.

This study aimed to assess the suitability of the selected literary texts through the preservice teachers' lenses who have undergone practical teachings in schools. The comments by the pre-service teachers that led to this evaluation then illustrate their viewpoints on literary works and the difficulties that may arise when utilizing these texts to teach English. It is believed that since teachers are the actual implementors of the texts in the English classroom, their evaluations, standpoints, and perspectives may contribute to the current study to raise the standard of English instruction.

Overall, the findings revealed that the study results came out relatively positive in which all the five texts are considered suitable for the learners. Besides choosing and selecting texts that cater to language learners' level of proficiency, the theme and issues discussed should be in line with learners' interest, thus making the selection for literary texts with the target learners in mind is essential.

We discovered that many themes recurred throughout the texts, including nationalism, the maintenance of traditions and ways of life, and family relationships, and the need to support one another. Although the texts addressed themes of family relationships, cross-cultural interactions, and the formation of ethnic and cultural identity hierarchies, they did not bring the Malaysian perspective into the classroom, nor did they promote inter-ethnic engagement.

These findings are consistent with those of Pillai et al. (2016), who found a narrowing of the space for local Malaysian literature in English, with none of the writings expressing ethnic diversity or cultural points within the Malaysian environment. The fact that the mandated texts provided to the learners are all either modified or taken directly from books and written materials from other countries might be a contributing factor.

The inclusion of only Eurocentric texts confirms the privileging of Western texts over local literature. The learners may find it challenging to connect the texts to their own experiences and way of life (Kebede \& Milkitie, 2018). As a result, books must first be assessed to verify their appropriateness for learners in Malaysian schools in terms of cultural factors. As a solution to this issue, the inclusion of local Malaysian literature in the teaching of inter-ethnic interaction in Malaysian schools is suggested. To promote the latter, classroom activities will focus on encouraging learners to interpret literary texts as openings to the various cultural spectrums in which they live and to build knowledge about the ways of experiencing, learning, and ultimately 
Arab World English Journal (AWEJ) Volume 12. Number 4. December 2021

The Voice of Learners on English Literary Texts

Abdul Samat, Azmi, \& Abdullah

understanding the many cultural worlds that exist both within and outside the familiar environment (Pillai et al., 2016).

Acknowledgments The research is funded by Universiti Teknologi Malaysia under the research grant no. Q.J130000.2606.18J41.

\section{About the Authors:}

Dr. Norhanim Abdul Samat. She had her doctorate in process drama from the University of Waikato, New Zealand. She is a teacher trainer attached to University Teknologi Malaysia. Her areas of expertise are Applied Literature, Drama Education, Communication and Language Arts Education, Student Development, and Community Learning. ORCiD ID: https://orcid.org/00000003-0110-5798

Nur Alwani Syahirah Azmi is a part-time lecturer in the Academy of Language Studies at Universiti Teknologi MARA where she taught first-year diploma students Integrated Language Skills. Her areas of interest are literacy studies, creative writing, materials development, and design. ORCiD ID: https://orcid.org/0000-0002-6582-0291

Dr. Tina Abdullah: A senior lecturer at Universiti Teknologi Malaysia with more than 25 years of teaching experience in communication courses for undergraduates and postgraduate levels. Actively involved as a teacher trainer for the Teaching of English as a Second Language program, her areas of interest are in Literature in English Language Teaching, Generative Thinking, Meaning Making, and Materials Development for Classroom Practice.

ORCiD ID: https://orcid.org/0000-0003-4551-658

\section{Reference}

Abdullah, I. H., \& Hashim, R. S. (2007). A readability analysis of Malaysian short stories in English. E-BANGI: Journal of Social Sciences and Humanities, 2(2), 1-11.

Arshad, M., Othman, A. J., \& Chew, F. P. \&. (2009). Reading comprehension of multi-ethnic literature in a multi-ethnic classroom: A case study of Malaysia. EDUCARE: International Journal for Educational Studies, 1(2), 119-128.

Bobkina, J., \& Dominguez, E. (2014). The use of literature and literary texts in the EFL classroom; between consensus and controversy. International Journal of Applied Linguistics and English Literature, 3(2), 248-260. https://doi.org/10.7575/aiac.ijalel.v.3n.2p.248

Calafato, R. \& Gudim, F. (2020). Literature in contemporary foreign language school textbooks in Russia: Content, approaches, and readability. Language Teaching Research, $1-21$.

Chitravelu, N., Sithamparam, S., \& Teh, S.C. (2008). ELT Methodology Principles and Practice. Shah Alam, Fajar Bakti.

Collie, J., \& Slater, S. (1990). Literature in the Language Classroom. A Resource Book of Ideas and Activities. Cambridge Handbooks for Language Teachers.

Cunningsworth, A. (1995). Choosing Your Coursebooks. Oxford, Maxmillian Heienman ELT.

Degwale, Y. \& Gashaye, S. (2020). Representation of Literary Texts in English for Ethiopian Textbooks and Their Practice in the Classroom: Grade 9 and 10 in Focus. Theory and 
Arab World English Journal (AWEJ) Volume 12. Number 4. December 2021

The Voice of Learners on English Literary Texts

Abdul Samat, Azmi, \& Abdullah

Practice in Language Studies, 10 (6), p. 623-631.

Ford, M. (2008). Five Short Plays. Oxford University Press, USA.

Ghazali, S. N., Setia, R., Muthusamy, C., \& Jusoff, K. (2009). ESL students' attitude towards texts and teaching methods used in literature classes. English Language Teaching, 2(4), 51-56. https://doi.org/10.5539/elt.v2n4p51.

Gower, R., \& Pearson, M. (1986). Reading Literature. London, Longman. Hill.

Gopal, R., \& Mahmud, C. T. (2016). An Examination of Literary Texts Prescribed for Lower Secondary Schools. Proceedings of the Teacher's Efforts to Overcome Students' Difficulties in Reading Comprehension, 358-361. ISSN: 2527-8037

Hall, G. (2005). Literature in Language Education. London, Palgrave Macmillan.

Ho, M. (n.d.). Tanjong Rhu in Literature Component for Secondary Schools Form 4 Leaving No Footsteps: Stories from Asia Retold by Clare West. Selangor, Zirwan Sdn. Bhd.

Kay, J. (n.d.). Living Photograph in Literature Component for Secondary Schools Form 4 \& Form 5: A Poison Tree: A Poetry Collection Selected by Pie Corbett and Valerie Bloom (Student's Edition). Selangor, Danalis Distributors Sdn Bhd.

Kebede, G. A., \& Milkitie, Y. M. (2018). A panoramic evaluation of literary texts in preparatory students' English textbooks. Theory and Practice in Language Studies, 8(8), 996-1004. https://doi.org/10.17507/tpls.0808.11

Khatib, M., Derakhshan, A., \& Rezaei, S. (2011). Why \& why not literature: A task-based approach to teaching literature. International Journal of English Linguistics, 1(1), 213-218. https://doi.org/10.5539/ijel.v1n1p213

Lathif, M. (2015). An evaluation of English textbooks for the eighth grades of junior high school. Faculty of Languages and Arts Yogyakarta State University.

Maley, A. (1989). Down from the pedestal: Literature as a resource. In R. Carter, R.Walker, \& C. Brumfit (eds.), Literature and the learner: methodological approaches. Modern English Publications and the British Council.

Masyi'ah, A. N., \& Ciptaningrum, D. S. (2018). An analysis and evaluation of two English textbooks for second graders of junior high school. LingTera, 5(1), 32-40. https://doi.org/10.21831/lt.v5i1.14931

Maxwell, J. A. (2012). Qualitative Research Design: An Interactive Approach. Thousand Oaks, California, Sage Publications.

Mukundan, J., Nimehchisalem, V., \& Haji Mohammadi, R. (2011). Developing an English language textbook evaluation checklist: A focus group discussion. International Journal of Humanities and Social Science, 1(12), 100-106.

Mussa, S. \& Fente, G. (2020). The Appropriateness of Literary Texts in Teaching Reading Skills: The Case of Some Selected High Schools in Ethiopia, Theory, and Practice in Language Studies, 10 (10), 1200-1209.

O'Keeffe, L., \& O'Donoghue, J. (2015). A role for language analysis in Mathematics textbook analysis. International Journal of Science and Mathematics Education, 13(3), 605-630. https://doi.org/10.1007/s10763-013-9463-3.

Pillai, S., Menon, P. S., \& Vengadasamy, R. (2016). The marginalization of Malaysian texts in the English language curriculum and its impact on social cohesion in Malaysian classrooms. Kajian Malaysia, 34(2), 25-58. https://doi.org/10.21315/km2016.34.2.2

Sanub, O., \& Yunus, M. M. (2016). English Literary Texts used in Form Four and Five English Literature Component 'Revisit'. International Conference on Education 2016, 688-694. 
Sivapalan, S., \& Subramaniam, G. (2008). The incorporation of literature in the English language program for engineering students: learner interest and perception. $3 L$ : Language, Linguistics, Literature, 14, 45-73.

Tennyson, L. A. (n.d.). Charge of the Light Brigade. Literature Component for Secondary Schools Form 4 \& Form 5: A Poison Tree: A Poetry Collection Selected by Pie Corbett and Valerie Bloom (Student's Edition). Selangor, Danalis Distributors Sdn Bhd.

Tevdovska, E. S. (2016). Literature in ELT setting: Students attitudes and preferences towards literary texts. Procedia-Social and Behavioral Sciences, 232, 161-169.

Tomlinson, B. (2001). Humanizing the coursebooks. In B. Tomlinson (ed.), Materials development for language teaching. Continuum (p. 143-179). Cambridge University Press.

Vassanji, M.G. (n.d.). Leaving: Literature Component for Secondary Schools Form Changing their Skies: Stories from Africa Retold by Jennifer Bassett. Selangor, Zirwan Sdn. Bhd. 